CLINICAL STUDY

\title{
Increased suppression of serum ghrelin concentration by hyperinsulinemia in women with anorexia nervosa
}

\author{
Monika Karczewska-Kupczewska, Marek Strączkowski, Agnieszka Adamska, Agnieszka Nikołajuk, \\ Elżbieta Otziomek, Maria Górska and Irina Kowalska \\ Department of Endocrinology, Diabetology and Internal Medicine, Medical University of Bialystok, M. Curie-Sklodowskiej 24A, 15-276 Bialystok, Poland \\ (Correspondence should be addressed to I Kowalska; Email: irinak@poczta.onet.pl)
}

\begin{abstract}
Context: Ghrelin is a peptide secreted mainly by the stomach, which has the ability to stimulate appetite and food intake. Serum ghrelin concentration decreases rapidly after a meal, probably because of the concurrent increase in serum insulin. Anorexia nervosa (AN) is an eating disorder, which is characterized by high serum ghrelin concentration; however, the regulation of circulating ghrelin by insulin in this disorder remains unclear.

Objective: To estimate serum ghrelin concentration in the fasting state and after hyperinsulinemia in women with AN.

Design and participants: We examined 19 women with AN, 26 lean healthy women, and 25 women who were overweight or obese. Serum ghrelin concentration was measured in the fasting state and after euglycemic hyperinsulinemic clamp.

Results: Insulin sensitivity was similar in AN and normal-weight women, and was markedly decreased in the obese subjects. In the fasting state, serum ghrelin was higher in AN group than in other groups (normal-weight, $P=0.017$; obese, $P=0.0001$ ) and in normal-weight women than in obese women $(P=0.044)$. Hyperinsulinemia resulted in a marked decrease in serum ghrelin in $\mathrm{AN}(P<0.0001)$ and normal-weight women $(P=0.002)$. The fall in serum ghrelin was higher in AN group than in other groups (normal-weight, $P=0.0008$; obese, $P=0.0001$ ), and was related to insulin sensitivity $(r=0.24, P<0.05)$. In multiple regression analysis, only fasting serum ghrelin and the presence of AN were independent predictors of this fall.

Conclusions: Women with AN have an increased suppression of serum ghrelin by hyperinsulinemia. This phenomenon might lead to an increased and more rapid feeling of satiety in AN.
\end{abstract}

European Journal of Endocrinology 162 235-239

\section{Introduction}

Ghrelin, a 28-amino acid peptide, was discovered as the endogenous ligand for the $\mathrm{GH}$ secretagogue-receptor (1). The stomach is the primary source of circulating ghrelin, but it is also produced in small amounts by the central nervous system and other peripheral tissues (1).

Ghrelin is a stimulator of GH release, but the major physiological role of ghrelin appears to be the control of food intake and energy homeostasis (2). Its orexigenic effects seem to be mediated through the activation of neuropeptide $\mathrm{Y}$ and agouti gene-related protein neurons in the hypothalamic arcuate nucleus and also neurons expressing orexin in the lateral hypothalamic area (2). Circulating levels of ghrelin decrease with feeding and increase before meals. Ghrelin peaks before meals, suggesting its role in short-term meal initiation. Ghrelin is also involved in the long-term regulation of body weight. Its concentrations depend on energy stores and manifest compensatory changes in response to body weight alterations (3). Indeed, plasma ghrelin concentration is low in obese people and high in lean people (4). Related to this, plasma ghrelin levels are highly increased in anorexia nervosa (AN) patients and return to normal after weight gain (5).

It has been hypothesized that insulin could be a physiological modulator of plasma ghrelin concentration. The low fasting plasma insulin could lead to an increase in ghrelin, while postprandial insulin release would suppress plasma ghrelin concentration (6). Insulin is probably essential for postprandial regulation of plasma ghrelin concentrations, and thus it might have an impact on modulating the feeling of hunger and satiety.

$\mathrm{AN}$ is an eating disorder characterized by decreased caloric intake, chronically low weight, disturbed body image, and pervasive fear of fatness (7). Regulation of circulating ghrelin by insulin in anorectic subjects remains unclear. Therefore, in the present study we aimed to estimate serum ghrelin concentration in the fasting state and after hyperinsulinemia in women with AN. 


\section{Subjects and methods}

\section{Participants}

We examined 19 women with AN (body mass index (BMI) $\left.<18 \mathrm{~kg} / \mathrm{m}^{2}\right) ; 26$ healthy, normal-weight female controls (BMI between 19 and $25 \mathrm{~kg} / \mathrm{m}^{2}$ ); and 25 women who were overweight or obese (BMI $>25 \mathrm{~kg} / \mathrm{m}^{2}$ ). All women with a restrictive type of AN met the criteria defined in the revised Diagnostic and Statistical Manual of Mental Disorders (8), and were recruited from the Department of Endocrinology, Diabetology and Internal Medicine, Medical University of Bialystok and from the Psychosomatic Clinic of Medical University of Bialystok. The mean duration of the disease was $16.8 \pm 11.6$ (range 6-36) months. All anorectic women without a history of weight regain had been weight stable for at least 1 month before the study. Women who were obese and control subjects were recruited from the outpatient clinic of our department, from the collaborating primary care practice, and from the medical staff and students. All subjects were nonsmokers, without serious diseases (other than AN) and morbid obesity, and were not taking any drugs. Before entering the study, physical examination and appropriate laboratory tests were performed. Analyses were performed after an overnight fast. All subjects underwent an oral glucose tolerance test (OGTT), and all had normal glucose tolerance according to WHO criteria. The study protocol was approved by the ethics committee of the Medical University of Bialystok. All the subjects gave written informed consent before entering the study.

\section{Anthropometry}

Anthropometric parameters were measured in all subjects. The BMI was calculated as body weight $\times$ height $^{-2}$, and is expressed in $\mathrm{kg} / \mathrm{m}^{2}$. The waist circumference was measured at the smallest circumference between the rib cage and the iliac crest, with the subject in the standing position. The percent of body fat was assessed by bioelectric impedance analysis using the Tanita TBF-511 Body Fat Analyzer (Tanita Corp., Tokyo, Japan) as described previously (9).

\section{Insulin sensitivity}

Insulin sensitivity was evaluated by the euglycemic hyperinsulinemic clamp technique according to DeFronzo et al. (10) as described previously (11). The whole-body glucose uptake ( $M$ value) was calculated as the mean glucose infusion rate from 80 to $120 \mathrm{~min}$, which was corrected for glucose space and normalized per kilogram of fat-free mass (ffm).

\section{Laboratory analyses}

Serum ghrelin concentration was measured before and after the clamp. Plasma glucose, serum insulin, and lipids were analyzed as described previously (11).
Before the estimation of the concentrations of ghrelin and insulin, the samples were kept frozen at $-80{ }^{\circ} \mathrm{C}$. The concentration of serum total ghrelin was measured using the RIA method (Linco Research, St Charles, MI, USA) with sensitivity of $93 \mathrm{pg} / \mathrm{ml}$ and with intra-assay and inter-assay coefficient of variation values below 10.0 and $14.7 \%$ respectively.

\section{Statistical analysis}

The statistics were performed with the STATISTICA 8.0 (Statsoft, Krakow, Poland). The variables that did not have normal distribution (fasting and postload insulin, triglycerides, and serum ghrelin) were log-transformed before analyses. For the purpose of the data presentation, these variables were again antilog-transformed to absolute values in the Results section. To estimate the differences between the groups, one-way ANOVA with post-hoc Tukey's test was performed. To assess the differences in serum ghrelin before and after the clamp, paired Student's $t$-test was used. Relationships between variables were analyzed with the Pearson productmoment correlation analysis and with the multiple regression analysis. The level of significance was accepted at a $P$ value that was lower than 0.05 .

\section{Results}

Clinical characteristics of the studied groups are given in Table 1. Insulin sensitivity was not different between AN and normal-weight women, whereas it was markedly lower in obese women than in the abovementioned groups (AN, $P=0.002$; normal-weight, $P=0.001)$. Steady-state serum insulin levels tended to be higher in the obese group; however, this difference did not reach statistical significance (AN, 99.37 \pm 37.30 ; normal-weight, $107.75 \pm 26.68$; obese, $134.33 \pm 56.19 \mu \mathrm{IU} / \mathrm{ml}$ ).

Fasting and post-clamp serum ghrelin concentrations are shown in Fig. 1. In the fasting state, serum ghrelin was higher in AN women than in other groups (normal-weight, $P=0.017$; obese, $P=0.0001$ ) and in normal-weight women than in the obese women $(P=0.044)$. Hyperinsulinemia resulted in a marked decrease in serum ghrelin in AN $(P<0.0001)$ and normal-weight women $(P=0.002)$, but not in the obese group $(P=0.57)$. The fall in serum ghrelin was significantly higher in the AN group than in other groups (normal-weight, $P=0.0008$; obese, $P=0.0001$ ). Use of the percent ghrelin change from the initial value instead of the absolute change gave essentially the same results. Post-clamp serum ghrelin was not different among the groups.

In the entire study population, fasting serum ghrelin was inversely related to BMI, waist circumference, percentage body fat, and fasting and postload glucose and insulin (all $P<0.005$ ), and it was positively related to insulin sensitivity $(r=0.32, P=0.007)$. All these 
Table 1 Anthropometric, biochemical, and metabolic characteristics of the studied groups.

\begin{tabular}{lccc}
\hline & AN group $(n=19)$ & Normal-weight group $(n=26)$ & Obese group $(n=25)$ \\
\hline Age (years) & $22.00 \pm 4.80$ & $25.69 \pm 5.36$ & $25.04 \pm 5.76$ \\
Body weight $(\mathrm{kg})$ & $43.93 \pm 3.40^{*}$ & $61.40 \pm 6.39$ & $90.09 \pm 13.83^{*, \dagger}$ \\
BMl $\left(\mathrm{kg} / \mathrm{m}^{2}\right)$ & $15.89 \pm 1.19^{*}$ & $22.00 \pm 1.75$ & $31.95 \pm 4.97^{*, \dagger}$ \\
Waist $(\mathrm{cm})$ & $61.39 \pm 3.15^{*}$ & $72.31 \pm 5.25$ & $98.38 \pm 15.43^{*, \dagger}$ \\
Percent of body fat & $12.93 \pm 4.15^{*}$ & $25.64 \pm 5.47$ & $40.67 \pm 5.83^{*, \dagger}$ \\
Fasting glucose $(\mathrm{mg} / \mathrm{dl})$ & $72.94 \pm 9.42^{*}$ & $80.49 \pm 7.45$ & $83.36 \pm 8.87^{\dagger}$ \\
Postload glucose $(\mathrm{mg} / \mathrm{dl})$ & $77.10 \pm 23.29$ & $84.59 \pm 16.33$ & $95.05 \pm 21.90^{\dagger}$ \\
Fasting insulin $(\mu \mathrm{lU} / \mathrm{ml})$ & $6.44 \pm 2.37^{*}$ & $12.16 \pm 5.96$ & $20.17 \pm 10.66^{*, \dagger}$ \\
Postload insulin $(\mu \mathrm{mol} / \mathrm{l})$ & $24.86 \pm 16.65$ & $37.21 \pm 16.24$ & $84.65 \pm 78.09^{\dagger}$ \\
Total cholesterol $(\mathrm{mg} / \mathrm{dl})$ & $172.02 \pm 30.84$ & $179.11 \pm 26.00$ & $166.68 \pm 26.03$ \\
Triglycerides $(\mathrm{mg} / \mathrm{dl})$ & $77.87 \pm 39.03$ & $64.42 \pm 18.20$ & $98.81 \pm 49.89^{*}$ \\
HDL-cholesterol $(\mathrm{mg} / \mathrm{dl})$ & $57.58 \pm 11.73$ & $64.01 \pm 10.43$ & $58.17 \pm 9.32$ \\
LDL-cholesterol $(\mathrm{mg} / \mathrm{dl})$ & $98.54 \pm 28.60$ & $102.12 \pm 24.69$ & $88.81 \pm 24.09$ \\
M (mg/kgffm per min) & $10.50 \pm 2.79$ & $10.27 \pm 3.26$ & $6.86 \pm 3.40^{*, \dagger}$ \\
\hline
\end{tabular}

Data are presented as mean \pm S.D. ${ }^{*} P<0.05$ versus normal-weight women. ${ }^{\dagger} P<0.05$ in obese women versus AN women. All signs of significance are taken from post-hoc Tukey's test, which was performed when one-way ANOVA gave a significant result.

associations (except fasting glucose) were also present in the obese group. The fall in serum ghrelin during the clamp was inversely associated with BMI, waist, percentage body fat, and fasting and postload glucose and insulin (all $P<0.05$ ), and it was positively associated with insulin sensitivity $(r=0.24, P=0.049)$ and baseline serum ghrelin $(r=0.76, P<0.0001)$ in the entire cohort. The correlation of the fall in serum ghrelin with its baseline values was also present in AN $(r=0.73, P=0.001)$ and normal-weight women $(r=0.81, P<0.001)$.

In the multiple regression analysis, the presence of AN $(\beta=0.46, P=0.008)$ and baseline serum ghrelin $(\beta=0.67, P<0.0001)$ determined the fall in serum ghrelin during the clamp independently of each other, and independently of age, BMI, and insulin sensitivity.

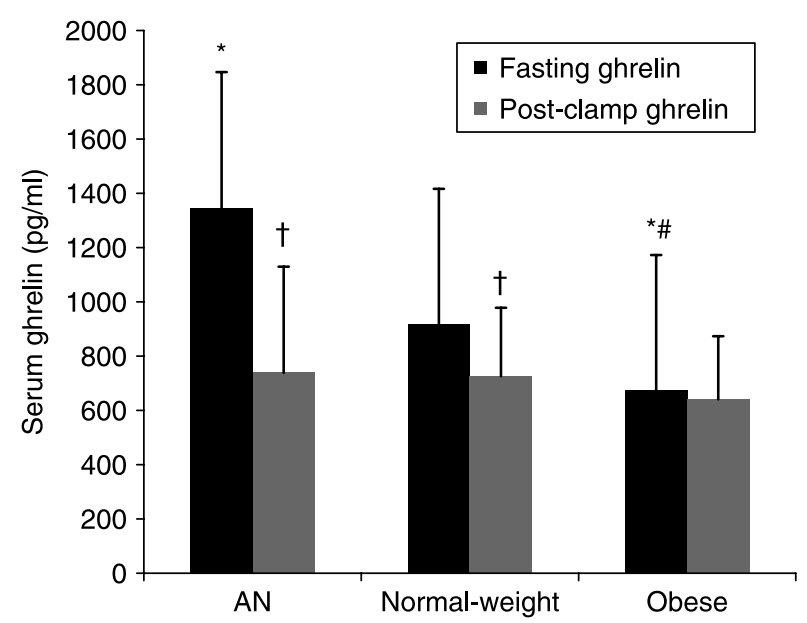

Figure 1 Fasting and post-clamp serum ghrelin concentrations in the studied groups. Data are presented as mean + S.D. ${ }^{\star} P<0.05$ versus normal-weight women. ${ }^{\#} P<0.05$ in obese women versus AN women. All signs of significance are taken from post-hoc Tukey's test, which was performed when one-way ANOVA gave a significant result. ${ }^{\dagger} P<0.05$ from paired Student's $t$-test for the difference between fasting and post-clamp ghrelin values within the studied groups.

\section{Discussion}

The main finding of our study is the presence of an increased suppression of serum ghrelin by hyperinsulinemia in women with AN.

We reported the highest fasting serum ghrelin levels in patients with $\mathrm{AN}$ and the lowest in the obese group. These data are consistent with the findings of previous studies $(4,5)$. It was reported that low plasma ghrelin levels are independently associated with fasting insulin levels and insulin resistance in humans (12). Misra et al. discovered that insulin resistance remained the sole significant predictor of circulating ghrelin concentration (13). We report significant positive correlation between fasting ghrelin and insulin sensitivity. In the present study, the inverse relationship between fasting insulin and ghrelin was also observed. The normal insulin sensitivity and the concurrent lower fasting insulin levels in patients with $\mathrm{AN}$ might lead to increased ghrelin concentrations. The progressive decline in circulating insulin would favor ghrelin production in AN.

Nutritional factors seem to play an important role in modulating ghrelin secretion. Fasting ghrelin levels decreased by meal intake (14) and oral or i.v. administration of glucose but not by gastric distension by water (4). The postprandial ghrelin suppression could influence satiety perception and have an impact on modulating feeding behavior. Insulin could mediate the effect of nutrition on postprandial regulation of plasma ghrelin concentrations (15). In humans, during a euglycemic hyperinsulinemic clamp, circulating insulin levels similar to or higher than those occurring after meal ingestion have been reported to suppress plasma ghrelin concentrations (6), and also its acylated form (16), which accounts for $\sim 10 \%$ of total ghrelin and contains an n-octanoylated serine 3 (Ser-3) residue that is essential for its orexigenic and GH-releasing action (1). 
Our results demonstrate for the first time an increased suppression of serum ghrelin by hyperinsulinemia in women with AN. We observed a marked decrease in serum ghrelin in AN subjects and normalweight women, but the fall in serum ghrelin was significantly higher in AN subjects than in normalweight and obese subjects, although steady-state insulin concentrations were not significantly different among the studied groups. Furthermore, there were no significant differences in insulin sensitivity between AN subjects and controls. In multiple regression analysis, only fasting serum ghrelin and the presence of AN, but not insulin sensitivity, were independent predictors of the fall in serum ghrelin during the clamp. These data suggest that this effect might be specific for $\mathrm{AN}$; however, its mechanism remains unclear. Increased suppression of serum ghrelin by insulin might lead to an increased and more rapid feeling of satiety in AN women. On the other hand, reduced food intake in AN despite chronically increased fasting ghrelin levels could reflect a decreased sensitivity to the effect of ghrelin on hunger (13).

Nakai et al. reported that short-term secretory regulation of ghrelin during OGTT in patients with AN was similar to that in normal controls, despite the higher plasma levels of ghrelin in these patients than in controls (17). On the other hand, the loss of mealinduced decrease in plasma ghrelin levels was observed in AN, suggesting an impaired suppression of hunger in this disease (18). Furthermore, some other authors suggested inadequate suppression of ghrelin secretion with oral glucose in anorectic subjects (19). In this study, ghrelin values did decrease in AN subjects after glucose administration, but remained significantly higher in AN subjects than in controls, while the extent of ghrelin suppression in AN subjects did not differ from that in controls. The difference between our results and other studies might come from different experimental conditions, differences in subjects' characteristics (for instance, adolescent girls in one study) (19), and low number of subjects recruited (five AN women in two studies) $(17,18)$.

We showed the lack of ghrelin suppression after the clamp in the obese group. These data are similar to previous findings $(20,21)$ on impaired postprandial ghrelin suppression in obesity, which could influence decreased satiety perception and may contribute to resistance to weight loss in obese patients (21).

In conclusion, women with AN have an increased suppression of serum ghrelin by hyperinsulinemia. This phenomenon might lead to an increased and more rapid feeling of satiety in AN women.

\section{Declaration of interest}

The authors declare that there is no conflict of interest that could be perceived as prejudicing the impartiality of the research reported.

\section{Funding}

This work was supported by the grant 3-50816L from the Medical University of Bialystok, Poland.

\section{References}

1 Kojima M, Hosoda H, Date $Y$, Nakazato M, Matsuo H \& Kangawa K. Ghrelin is a growth-hormone-releasing acylated peptide from stomach. Nature $1999 \mathbf{4 0 2} 656-660$.

2 Korbonits M, Goldstone AP, Gueorguiev M \& Grossman AB. Ghrelin - a hormone with multiple functions. Frontiers in Neuroendocrinology 200425 27-68.

3 Cummings DE. Ghrelin and the short- and long-term regulation of appetite and body weight. Physiology and Behavior 200689 71-84.

4 Shiiya T, Nakazato M, Mizuta M, Date Y, Mondal MS, Tanaka M, Nozoe S, Hosoda H, Kangawa K \& Matsukura S. Plasma ghrelin levels in lean and obese humans and the effect of glucose on ghrelin secretion. Journal of Clinical Endocrinology and Metabolism 200287 240-244.

5 Otto B, Cuntz U, Fruehauf E, Wawarta R, Folwaczny C, Riepl RL, Heiman ML, Lehnert P, Fichter M \& Tschöp M. Weight gain decreases elevated plasma ghrelin concentrations of patients with anorexia nervosa. European Journal of Endocrinology 2001145 669-673.

6 Saad MF, Bernaba B, Hwu CM, Jinagouda S, Fahmi S, Kogosov E \& Boyadjian R. Insulin regulates plasma ghrelin concentration. Journal of Clinical Endocrinology and Metabolism $2002 \mathbf{8 7}$ 3997-4000.

7 Yager J \& Anderson AE. Anorexia nervosa. New England Journal of Medicine 2005353 1481-1488.

8 American Psychiatric Association Diagnostic and Statistical Manual of Mental Disorders. edn 4. Washington, DC: DSM-IV-TR. 2000.

9 Karczewska-Kupczewska M, Straczkowski M, Adamska A, Nikolajuk A, Otziomek E, Gorska M \& Kowalska I. Insulin sensitivity, metabolic flexibility and serum adiponectin concentration in women with anorexia nervosa. Metabolism: Clinical and Experimental, 2009 In Press. DOI: 10.1016/j.metabol. 2009.07 .036$.

10 DeFronzo RA, Tobin JD \& Andres R. Glucose clamp technique: a method for quantifying insulin secretion and resistance. American Journal of Physiology 1979237 E214-E223.

11 Kowalska I, Straczkowski M, Nikolajuk A, Krukowska A, Kinalska I \& Gorska M. Plasma adiponectin concentration and tumor necrosis factor-alpha system activity in lean nondiabetic offspring of type 2 diabetic subjects. European Journal of Endocrinology 2006154 319-324.

12 Pöykkö SM, Kellokoski E, Hörkkö S, Kauma H, Kesäniemi YA \& Ukkola O. Low plasma ghrelin is associated with insulin resistance, hypertension, and the prevalence of type 2 diabetes. Diabetes 2003 52 2546-2553.

13 Misra M, Miller KK, Kuo K, Griffin K, Stewart V, Hunter E, Herzog DB \& Klibanski A. Secretory dynamics of leptin in adolescent girls with anorexia nervosa and healthy adolescents. American Journal of Physiology. Endocrinology and Metabolism 2005 289 E373-E381.

14 Williams DL, Cummings DE, Grill HJ \& Kaplan JM. Meal-related ghrelin suppression requires postgastric feedback. Endocrinology $20031442765-2767$.

15 Murdolo G, Lucidi P, Di Loreto C, Parlanti N, De Cicco A, Fatone C, Fanelli CG, Bolli GB, Santeusanio F \& De Feo P. Insulin is required for prandial ghrelin suppression in humans. Diabetes $2003 \mathbf{5 2}$ 2923-2927.

16 St-Pierre DH, Karelis AD, Coderre L, Malita F, Fontaine J, Mignault D, Brochu M, Bastard JP, Cianflone K, Doucet E, Imbeault P \& Rabasa-Lhoret R. Association of acylated and 
nonacylated ghrelin with insulin sensitivity in overweight and obese postmenopausal women. Journal of Clinical Endocrinology and Metabolism 200792 264-269.

17 Nakai Y, Hosoda H, Nin K, Ooya C, Hayashi H, Akamizu T \& Kangawa K. Plasma levels of active form of ghrelin during oral glucose tolerance test in patients with anorexia nervosa. European Journal of Endocrinology 2003149 R1-R3.

18 Nedvídková J, Krykorková I, Barták V, Papezová H, Gold PW, Alesci S \& Pacak K. Loss of meal-induced decrease in plasma ghrelin levels in patients with anorexia nervosa. Journal of Clinical Endocrinology and Metabolism $2003 \mathbf{8 8} 1678-1682$.

19 Misra M, Miller KK, Herzog DB, Ramaswamy K, Aggarwal A, Almazan C, Neubauer G, Breu J \& Klibanski A. Growth hormone and ghrelin responses to an oral glucose load in adolescent girls with anorexia nervosa and controls. Journal of Clinical Endocrinology and Metabolism 200489 1605-1612.

20 English PJ, Ghatei MA, Malik IA, Bloom SR \& Wilding JP. Food fails to suppress ghrelin levels in obese humans. Journal of Clinical Endocrinology and Metabolism 200287 2984-2987.

21 Greenman Y, Golani N, Gilad S, Yaron M, Limor R \& Stern N. Ghrelin secretion is modulated in a nutrient- and gender-specific manner. Clinical Endocrinology 200460 382-388.

Received 14 October 2009

Accepted 30 October 2009 